Assessment or Referral Tool: The Unintended Consequences of a Dual Purpose Common Assessment Framework Form.

Acknowledgements

I would like to thank colleagues for their support and guidance, particularly Bethan MichaelFox

Author Details

Dr Kathryn Nethercott

University of Bedfordshire

Education Studies Department

Polhill Avenue

Bedford

MK41 9EA

Email Kathryn.nethercott@beds.ac.uk

Phone 01234793286 


\title{
Assessment or Referral Tool: The Unintended Consequences of a Dual Purpose Common Assessment Framework Form.
}

\author{
Abstract \\ The Common Assessment Framework (CAF) was designed to facilitate early intervention \\ through multi-agency working and the active involvement of families. The underlying \\ principle was to move away from a risk focused, needs led or service led culture to assess \\ need and match needs to identified services. It was anticipated that services and \\ assessments would become more evidence based, and a common language between \\ professionals and agencies would evolve.
}

Taking a social constructionist approach this study explored professionals' experiences of the use of the Common Assessment Framework form. Forty-one professionals from four different local authorities and a variety of agencies took part in semi-structured interviews. Data were analysed utilising thematic analysis.

Findings suggest the unintended consequences of the use of the CAF were influenced by local authority policy. As the local authorities adopted the policy of utilising the CAF as a referral mechanism, rather than to assess needs, professionals unintentionally perceived the CAF form as a referral tool, to refer families to existing service provision. Further to this, professionals referred to the CAF form itself, as a 'means to an end', implying that this was a step which had to be overcome in order to access services.

Key Words: Common Assessment Framework, Multi-Agency Working, Assessment 


\section{Introduction}

A number of initiatives related to the social welfare of citizens within Britain have been introduced by central government in the UK. For example, supporting families was a key element of the Children Act (1989), which stated that Local Authorities have a duty to provide a range of services for all children considered to be in need within the local area. Regardless of the introduction of strategies to identify need and enhance family support, research has identified that on-going barriers to services remain. For example, despite changes to public policy highlighting the need for early intervention and multi-agency working, many families fail to receive services early enough as a result of high thresholds for service access (Sheppard, 2009; Sodha, 2009; Family Rights Group 2018; Children's Commissioner 2019). Within the Care Crisis Review (Family Rights Group 2018) many of the professionals interviewed commented on working in an environment, which was overstretched and not providing the early support families required.

The importance of early intervention and prevention was further emphasised by the Children Act (2004) with the Ministerial Introduction to Every Child Matters: Change for Children (DfES, 2004), stating; "The services that reach every child and young person have a crucial role to play in shifting the focus from dealing with the consequences of difficulties in children's lives to preventing things from going wrong in the first place" (p. 2). The Early Intervention Foundation (2018) stated early intervention services delivered at a high standard can fundamentally improve the lives of those children needing help and support. Furthermore, it is also widely advocated that providing preventative services is more cost effective than providing costly firefighting services that attempt to 'fix' problems once they have become entrenched (Allen \& Duncan-Smith, 2008; Allen, 2011; NEF 2012). This has been further emphasised in the more recent report published by the Children's Commissioner (2019) and the Care Crisis Review (2018), in which the authors called for a review on the lack of early, free and independent advice and support. However, Featherstone, Morris and White (2013) advocate for a clear common understanding of the term 'intervention', stating the situation as more of a 'now or never' (p. 5) circumstance for struggling families with interventions being delivered to families rather than working with families to recognise their strengths and vulnerabilities. 
Adopting a social constructionist approach this paper discusses one element of the findings from a PhD study that explored frontline professionals' use of the Common Assessment Framework (CAF) across four local authority areas in the south east of England. The paper focuses on the use of an initiative, the CAF, which was designed to facilitate early intervention of the kind mentioned above through multi-agency working and the active involvement of families.

\section{The Emergence of the Common Assessment Framework}

A number of government documents and guidance (Children Act 1989, DfES 2006, DfE 2012b) have stipulated that professionals should provide support to families in need of extra help. However, Munro (2011) asserts that family support services have not appeared as quickly as one would have hoped for. Barnes and Morris (2008) discuss a change in the focus from child protection that had been evident, in the early 1990s and before, to a focus on prevention and early intervention introduced by the New Labour government elected in 1997 . The new policies and initiatives concentrated on the social exclusion of children and repositioned families as partners (Morris, 2012). However, due to lack of family engagement in family support service and the complexity of family support services, need and thresholds, these new policies appeared to be somewhat futile in many circumstances. Indeed, Lucas (2017) has reported limited evidence of partnership working with young people. In response to research conducted for the Department for Education and Skills, by Pricewaterhouse Coopers in 2006, the New Labour government recognised a further shift in family support needs. The importance of parental and family influence was acknowledged, which led to an increase in funding for services.

Following this, within the Children Act (2004) there were a number of key proposals primarily designed to reduce child poverty. One of these was the need to produce guidance about how to respond to and monitor safeguarding referrals, including the development of common assessment frameworks (Corby, 2006). Along with this, the previous Labour government introduced many family orientated initiatives, including prevention and early intervention programmes, believing that more established problems are more difficult to deal with (Social Exclusion Task Force, 2007; DCFS, 2009; DfE, 2004).

These initiatives included the introduction of Children's Centres, aimed at helping and supporting parents of pre-school children, and the concept of 'Team Around the Child' 
(TAC). The sole purpose of the latter is a multi-agency approach to meet need, which includes the child and family in decisions about services or actions needed. The new proposals also incorporated the introduction of a new assessment process, the 'Common Assessment Framework' (2006). This was based upon the 'Framework for the Assessment of Children in Need and their Families' (DoH 2000, p. 10), a framework, which was thought to provide a systematic, holistic, and ecological approach to assessing need. It was based on research and theory across a range of different disciplines as well as replicating the underlying principles of the United Nations Convention on the Rights of the Child (1989).

To address previous concerns regarding the lack of identification of actual need as opposed to perceived need, the Common Assessment Framework was introduced within England in 2006 with the vision of this being fully implemented by 2008 (DfES 2006). This was presented to the social care sector as a "needs led", "strengths" and "evidence based" assessment process. This was heralded as a more holistic way of assessing children with additional needs, so the "child's, rather than the services', needs are at the centre" (DfES, 2006). The CAF was introduced as a universal tool which promoted early intervention, by helping professionals assess needs at a much earlier stage of development or difficulty, and encouraging practitioners to work closely with the families involved in collaboration with other professionals and agencies (DfES, 2006).

The underlying principle of the CAF was to move away from a risk focused needs led or service led culture to providing supportive services which were thought to match identified needs, with the child being central to the assessment process. The intention was to reduce the burden of multiple assessments for families, improve communication between professionals, parents, and different agencies, as well as to promote early detection of problems. This was in addition to the identification of early intervention work/services in order to "help them [family] before things reach crisis point" (CWDC, 2009 p. 11). Additionally, it was anticipated services and assessments would become more evidence based, and a common language between professionals and agencies would evolve, allowing for information to be shared in a more straight forward way. This information would follow the child, rather than families having to relay their stories to numerous different professionals (CWDC, 2009). 
However, White et al., (2009) found that a number of professionals struggled with the frame and structure of the form itself, claiming that it did not allow for the full narrative of families' stories to be told. Professionals either chose to omit answers from the form altogether, or gave scant information that was thought to be inadequate by other professionals who came into contact with the family. In addition to this, professionals were also found to be reluctant to offer information that they felt was not relevant to their own remit or expertise. White et al., (2009) concluded, "Professionals have their own ontologies, which CAF seeks to disrupt in the cause of creating a common, evidence-based language of need. This language of need can create, challenging, descriptive and interpretive demands for the CAF writer and reader" (p. 1213).

Brandon et al., (2006), Gilligan and Manby (2008), and White et al., (2009), Adamson and Deverell (2009) all found that the CAF was being utilised with a dual purpose: an assessment tool and a referral tool. White et al., (2009), in a study exploring the impact the CAF had on working practices, found, in areas where it was expected that all professionals would complete CAFs, take up by professionals working within private and voluntary organisations and health professionals was particularly low, whilst predominant use was found in professionals from education. This was a similar finding to Brandon et al., (2006), who found that the CAF was mainly utilised by professionals working within health and education. Adamson and Deverell (2009) reported difficulties with the length of the CAF process, particularly for professionals who were not familiar with the completion of a holistic assessment. In an attempt to combat this, some LAs have replaced the CAF with a shorter version, often referred to as an Early Help Assessment (EHA). Although this is shorter to complete, the EHA is based upon the original CAF form and remains to have the purpose of an assessment form. Other LAs continue to use the CAF form.

Holmes and McDermid (2016) reported; a lack of training for professionals adopting the Lead Professional Role and concerns about the level of responsibility the role required when considered with the training and experience of the professional. Similarly, Featherstone and Manby (2006) commented, assessments and referrals by schools were disproportionately being made in regard to boys who were presenting behaviour difficulties. The CAF was supposed to be a tool to be utilised to refer or assess all children with additional needs, but 
the authors argued that schools were using them inappropriately for support, to assist them with issues with behaviour management.

Despite the endeavours of the New Labour government, all of these findings were in direct contrast to the ideal that they had set out to achieve when the CAF was first introduced. It was believed it would serve as an assessment tool for all types of professionals and would enhance communication and commonality, but in reality it had quite the opposite effect. Brandon et al., (2006) concluded, in order for there to be some 'commonality' within the CAF processes, there was a requirement for further statutory guidance. As it stood, due to a lack of legislative guidance and too much flexibility, local authorities were allowed to integrate the CAF and related processes as they wished, in turn resulting in little or no 'commonality'. They concluded that the CAF, despite its name, was anything but common in either its functions or the way that it was used.

\section{Methodology}

The overarching aim of the research was to generate insights into the ways frontline practitioners, from a variety of professional backgrounds, understand the purpose of the Common Assessment Framework (CAF), as evidenced by their use of it. In order to understand this, an interpretivist approach was adopted utilising a social constructionist lens.

\section{Social Constructionism}

Social constructionism challenges the traditional view of knowledge being objective and unbiased. Through communication, social norms and practices emerge. These emerging behaviours become embedded within society and are constructed as part of societal customs and habits (Schwandt, 2003). Burr (1999) explains social constructionists believe that an ideal of 'truth', or a present understanding of the world, is not an objective observation, but a product of social processes and interactions. These beliefs vary from culture to culture and change according to contemporary ideals and social norms. She goes on to discuss, language and discourse have a particularly salient part to play in the constructions of ideals and norms within different societies. A word or phrase that means 
one thing for a particular culture can mean something completely different to another (Sahin, 2006).

Parton (2003) and Sahin (2006) both acknowledge, social constructionism is a particularly suitable ontology to utilise within studies exploring perceptions, and repeated experiences within professions such as social care and teaching. It is thought, the unpredictable nature of these professions lend themselves to reflection, communication, and subsequent changes to practice. Although elements of this type of work are suitable for quantitative studies, the changeable environment, as well as the nature of their work, are not obviously conducive to an objective, quantifiable, scientific measurement, but are more open to a subjective, qualitative study (Parton, 2003, Schon, 1983, 1987, Payne, 1997, Houston, 2001).

A qualitative approach to data collection was utilised in this study, as it allowed compilation of analysis of participants' own opinions and views. This resulted in data that were both rich and detailed and which conveyed individual experiences. The study adopted the use of oneto-one semi-structured interviews and a group interview, both of which are recognised techniques for collecting qualitative data.

\section{Data Collection Process}

To protect the identity of all participants and the local authorities, pseudonyms will be used throughout this paper. The four local authorities therefore are referred to as New Town, Old Town, District Town and Middle Town. During the study, data were collected in two separate time periods. The first stage of data collection took place within one Unitary Local Authority (LA), between February 2011 and February 2012. To uphold the anonymity of all participants and the LA involved, this LA will be referred to as New Town.

Professionals taking part in stage one were interviewed on three separate occasions. Conducting the interviews at three different time points allowed for the analysis of the data to look beyond the narrow point of time that is the referral point. Therefore the data also encompassed, from the perspective of the professional, what happened to the family and young person post referral. This was in addition to how much contact the referring professional had with the family after the referral process had completed. 
Data collection for stage two included two forms of interviews: semi-structured interviews with individual professionals in education from four different local authorities; and one group interview conducted in New Town with a diverse group of professionals who worked within one alternative education setting in the town, which catered for young people in education Key Stage three and four.

\section{Sample}

Data were collected in different locations consecutively. In both stages of this study, a purposive sampling method was utilised to recruit professionals who worked within multiagency environments and had completed a CAF form for a family or young person. In stage two, a refined sampling strategy was used. It was evident from previous research, regarding the use of the CAF (White, et al., 2009, Pithouse, et al., 2009 Collins \& McCray 2012) and the recruitment of participants in stage one of this study, those professionals associated with education were the professionals most experienced in completing the CAF. Therefore to enhance the data collected in stage one the second stage of the study saw data collected from professionals working within education in three further local authorities that were in the same area of England as New Town. These LAs will be referred to as Old Town, Middle Town and District Town. This data collection occurred between July and September 2014. 


\section{Sample Characteristics}

Stage one included twenty-nine referring professionals, twenty-eight women and one man, from a range of roles, who were interviewed in regard to thirty-six families whom they had referred for additional services within New Town.

Table 1: Professional Role of Participants in Phase One

\begin{tabular}{|l|c|c|}
\hline Role & $\mathbf{N}=$ & $\mathbf{\%}$ \\
\hline Family Support Worker & 6 & $21 \%$ \\
Education welfare Officer & 6 & $21 \%$ \\
Social Worker & 1 & $3 \%$ \\
Senior Tenancy Officer & 2 & $7 \%$ \\
Housing Tenancy Officer & 1 & $3 \%$ \\
Community Safety Officer & 1 & $3 \%$ \\
Assistant Head of House (Qualified Teacher) & 1 & $3 \%$ \\
Head of hearing impaired provision (Qualified Teacher) & 1 & $3 \%$ \\
Inclusion Officer (Qualified Teacher) & 2 & $7 \%$ \\
Pastoral leader (Qualified Teacher) & 1 & $3 \%$ \\
Senior Tutor-Head of Year (Qualified Teacher) & 1 & $3 \%$ \\
Special Educational Needs Co-ordinator (Qualified & 2 & $\mathbf{7 \%}$ \\
Teacher) & & \\
Teacher (Qualified Teacher) & 3 & $10 \%$ \\
Manager Learning support unit (Qualified Teacher) & 1 & $\mathbf{3 \%}$ \\
Total & $\mathbf{2 9}$ & $\mathbf{1 0 0 \%}$ \\
\hline
\end{tabular}

All of the participants in stage two were female. Six were qualified teachers working as Special Educational Needs coordinators. A further six professionals took part in the group interview. These participants had a variety of qualifications and roles.

Table 2: Professional role of the participants phase two

\begin{tabular}{|l|c|c|}
\hline Role & $\mathbf{N}=$ & $\mathbf{\%}$ \\
\hline Family Worker & 1 & $16 \%$ \\
Deputy Head teacher & 1 & $16 \%$ \\
Team Leader & 1 & $16 \%$ \\
Education Welfare Officer & 1 & $16 \%$ \\
Lead Tutor/Key Worker & 1 & $16 \%$ \\
Missing & 1 & $16 \%$ \\
Special Educational Needs Coordinator (SENCo) & 6 & $50 \%$ \\
Total & $\mathbf{1 2}$ & $\mathbf{1 0 0 \%}$ \\
\hline
\end{tabular}


As can be seen in the tables above, referring professionals worked within education, housing tenancy, community safety, and health. There was great diversity within the professional roles but workers within education settings completed the highest number of CAF forms

\section{Interviews}

All interviews, in phase one and two, were conducted by the author and were held within the professional's workplace at a time convenient to them. The initial interview in phase one (T1), was preceded by the professionals completing a short demographic questionnaire. Following this, the interview opened with the professional being asked about their professional role. The interview schedule was made up of three distinct sections, section one included questions regarding the family the professional was working with and any information the professional knew about the family. Information that was collected about the family, at this point, would have been covered in the completion of the CAF. The family remained anonymous at all times during the interview process. Section two explored professionals' own use and experience of the CAF process, whilst section three looked at the professionals' experiences of multi-agency working and professional communication.

The telephone interview at T2 was a brief discussion exploring the professionals' attendance at and experiences of the multi-agency panel meeting. The follow up interview at T3 took place up to three months after the multi-agency panel meeting. This interview explored the professionals' current relationship and knowledge of the family and their situation, in addition to any outcomes, the family may have experienced since the multi-agency panel meeting.

The interviews in phase two were informed by the initial data analysis of phase one. These interviews did not include any questions that were case based or any specific questions about attending the multi-agency panel. It did, however, include questions related to working in multi-agency ways. The interview schedule for phase two began with a set of demographic questions. This was followed by a set of questions that explored the professionals' use of the CAF and their experiences of this.

\section{Data collection technique}


Table 3: Data collection process for phase one and phase two

\begin{tabular}{|l|l|l|l|l|}
\hline & $\begin{array}{l}\text { T1: } \text { Prior to MA } \\
\text { panel meeting }\end{array}$ & $\begin{array}{l}\text { T2: Directly post } \\
\text { MA panel meeting }\end{array}$ & $\begin{array}{l}\text { T3: Up to 6 } \\
\text { months post MA } \\
\text { panel meeting }\end{array}$ & $\begin{array}{l}\text { Phase two } \\
\text { interviews }\end{array}$ \\
\hline $\begin{array}{l}\text { Participants in } \\
\text { phase one }\end{array}$ & $\begin{array}{l}\text { Face to face } \\
\text { interview }\end{array}$ & $\begin{array}{l}\text { Short telephone } \\
\text { interview }\end{array}$ & $\begin{array}{l}\text { Face to face } \\
\text { interview }\end{array}$ & $\begin{array}{l}\text { Focus group, face } \\
\text { to face or } \\
\text { telephone } \\
\text { participants in }\end{array}$ \\
\hline
\end{tabular}

As detailed in table three, during stage one pre (T1), post (T2) and follow-up (T3) interviews were conducted with twenty-nine professionals.

\section{Data Analysis}

Thematic analysis of the qualitative data was adopted as consistent with a social constructionist approach (Braun \& Clarke 2006). This allowed for the data to be trawled, searching for commonality and diversity in the way different professionals discuss and relayed their experiences of multi-agency working and their use of the CAF. Additionally, a thematic approach allowed the data analysis to explore how frontline professionals within varied work settings construct these phenomena.

Stage two data were merged and triangulated with stage one data at the point of analysis. This technique of analysis allowed for commonalities within the data to be identified and for contrasting views to be presented within different groups of professionals (Cresswell \& Clark, 2011).

Themes from the entire study included the intricacies of working within the referral process and the implications of these for the referring professionals, constraints within the process and barriers to access services and the relevance of professional knowledge. This article deals with the implications of working within the referral processes and how this is affected by professional knowledge, other findings have been discussed in other articles.

\section{Ethical Considerations}


The relevant ethics committee at the university concerned and the Local Authority Research Governance Panel granted ethical approval for both stages of this project. This process followed, and was in accordance with, the Economic Social Research Council (ESRC) (2010) Research Ethics Framework. In line with this, written informed consent was gained from all participants.

\section{Findings}

In order to access services, New Town used a specific referral route. As is the case in many LAs, a completed CAF form was a requirement of the referral process. The completed CAF was submitted to, and reviewed by, a Multi-Agency Panel (MAP), the expressed objective of which was to help attain better outcomes for children and their families. At the time of data collection, there were separate panels within the Local Authority, each covering a specific geographic area. Each panel consisted of professionals from different agencies and areas within the Local Authority, such as health, social care, and the voluntary sector. Referrals were generally received from a diverse group of professionals within universal, tier one and two services. Due to the nature of this process CAF forms were often completed prior to any TAC meetings that may have been attempted or taken place.

District Town and Old Town had similar referral mechanisms to the one adopted in New Town. Each LA utilised the CAF form as a tool to access supportive services that were commissioned by the LA, which were collated by a central team within the respective children's services departments. During 2014 Middle Town had moved away from the use of the CAF form and had implemented a shorter Early Help Assessment (EHA) form. The EHA incorporated a number of the questions from the CAF form and was utilised as a new referral tool. This initiative was implemented through consultation and feedback with professionals who had completed CAF forms in the past and had claimed that they were too long. A number of unintended consequences, of using the CAF form in this way, were identified. These included the way in which professionals perceived the CAF process and utilised the form and the completion process, the diversity of the professional body conducting CAF assessments and the specific implications of this for particular professionals. The tensions, which arose for some professionals, when trying to navigate the assessment process and complete the form. 


\section{Professional use of the Common Assessment Framework}

This section explores professionals' use of the CAF and how local policies informed the professionals' use and perceptions of the CAF system and form, in reference to the need to access services that had already been commissioned. Respondents, in both stages, used the CAF form to refer young people for a variety of reasons; these included behavioural issues, within school and local community areas, truanting from school, access to parenting support etc. Referrals were also conducted, in both stages, when professionals had safeguarding concerns. Some of the referrals had been completed at the parents' request in order to access parenting support with difficulties they were experiencing.

All participants identified themselves as the main point of contact with the families. However dependent upon their expertise and knowledge, they did not all identify as the Lead Professional for the family. Notably, those working within education or used to completing holistic assessments were the participants who, sometimes reluctantly, identified as the Lead Professional. For varying reasons very few Team Around the Child (TAC) meetings took place, this was often due to lack of time and resources and a reluctance of professionals from other agencies to attend meetings.

Whilst there was diversity in the causes of concern, all respondents were consistent in their use of the CAF. When introduced, the CAF was thought to be a holistic way of assessing families in need; however, in this study the CAF was often viewed as a "means to an end", a term which was used by numerous professionals across both stages of data collection. This perception of the CAF resulted from the way in which each local authority required professionals to access services for the children and young people with whom they were working. It was a requirement of all four of the local authorities that the CAF was used in order to access support services, which were commissioned from external agencies. This requirement resulted in all of the professionals, within this study, viewing the completion of the CAF form as the first step of a referral process, rather than an assessment tool. All of the respondents within the study, regardless of the local authority in which they were working or their professional background, indicated the completed CAF was for a referral and not used as a form of assessment. This was particularly evident within the groups of professionals who did not regularly work with children, young people, and their families. 
These professionals all stated that they had completed the CAF in order to access a particular service.

"Because that is our procedure any young person involved in anti-Social behaviour has a CAF form filled in so that we can refer to [service name]." (Housing Tenancy Officer, Stage one)

As has already been mentioned, there was diversity within the professionals completing the $\mathrm{CAF}$, with the largest group of completers being from education. Due to the nature of using the CAF form as a referral mechanism, rather than the intended assessment form professionals, who were ill equipped to complete a holistic assessment, found themselves using the CAF form. These included professionals from housing tenancy agencies and community safety roles and education welfare officers. Professionals who held these roles, which were by the very nature of them more enforcement than support agencies, found themselves torn between supporting the children, young people and families they were working with and working within their role of enforcement. Professionals who had a lack of understanding of the purpose of the CAF, as well as a lack of training in how to appropriately assess need, had difficulties both with completing the form as an assessment and including all relevant information that was required. Particular professionals, especially those working within 'enforcement agencies', did not always fully comprehend the information required. On these occasions, the respondents attempted to add evidence where they believed it was appropriate or, alternatively, if they felt the information was required but could not see where it fitted, they added detail to the margins and other areas of the form.

"I usually find that if someone tells me something I find a box to put it in or if there isn't then I scribble it down somewhere... I find somewhere to put it on the form to make it relevant." (Housing Tenancy Officer, Stage one)

It has to be noted that these practices of completing the form were directly related to the respondents in stage one working in enforcement roles.

Local Authority policies of use of the CAF form as a referral tool, rather than an assessment tool created particular conflicts in both professional and personal terms for these 
professionals working within roles that had a focus of enforcement. Professionals within these roles were particularly concerned about the conflicting and ambiguous information they were portraying to families. On the one hand they were informing families that they were enforcement agencies with very particular remits; in the most extreme cases they had the authority to remove the family's tenancy agreement or start court proceedings. Meanwhile, on the other hand, they were required to work with the family in a supportive way to access services. The completion of the CAF form entailed asking intrusive questions and attempting to glean extremely personal information out of the family. This presented the professionals with very specific problems in trying to engage families within the referral process. These respondents often remarked that they were not in the position to complete CAF forms and that it was highly inappropriate for them to be doing so.

“I am not necessarily liked by the people I visit. They don't want me in their house, so when I am asking personal questions about their family and children they don't want to talk to me and I don't blame them. So you know we are saying we can basically take your house away as we are the landlords." (Senior Tenancy Enforcement Officer, Stage one)

Each respondent, in this predicament, expressed the concern that she was not the appropriate professional to be completing this form. They were expected to ask intrusive questions and to work with families with whom relationships were often strained, but with whom they were required to cooperate in a meaningful way. This dichotomy, between enforcement and support, was confusing and contradictory for the professional and professionals commented on the confusion this created for the families with whom they were working. This resulted in neither the parent nor the professional knowing how to perceive the exchange which led to a relationship that professionals perceived, on both sides, as lacking in trust. Whilst the parent did not want to divulge personal information to the professional the professional doubted the honesty of the information being shared. This had the detrimental effect of professionals often speaking in negative terms of the families involved. This, in turn, created difficulties for these professionals who perceived the CAF process as not being part of either their working remit or responsibility. 
"Even if she gets fined again, ultimately, will that turn [young person] around I don't know, can't answer that, don't know. They get to year 10 and year 11 of school and they are just so strong, the families where there are entrenched poor parenting issues you have just lost them... It is so entrenched all the issues and everything." (Education Welfare Officer, Stage one)

Professionals, particularly those in 'enforcement roles' took part in the process reluctantly and saw it as a 'tick box' exercise, to be engaged with when necessity dictated that they had to be. This use of the CAF form, as a referral tool, led to confusion and uncertainty for all of the professionals involved. Whilst the CAF form is supposed to enhance partnership working with families the reality was, using it in this way had the opposite effect. Professionals, across both stages of the study, perceived that it created mistrust and doubt on their part and on the part of the parent, resulting in a lack of communication and cooperation.

\section{Professionals' Experiences of Working with the System}

As has been demonstrated, there was evidence of a number of frustrations and barriers with which all of the professionals, to varying degrees, were faced with. All of the professionals discussed annoyances with the process itself. However, despite these barriers and hindrances, respondents in stage one viewed the success of the referral experience based on the outcome for the family. Respondents in both stages, following local authority policy to use the CAF for referral rather than assessment, commenced the referral process and completed the assessment often with a particular service in mind. They were aware of their perceptions of the underlying problems, as well as the needs of the family and entered the process with an ideal solution rather than what would meet the needs of the family, as determined by the assessment of need. Whether the professional viewed the experience of the process positively or negatively was dependent upon this outcome. If they had managed to secure the desired outcome, or engaged the required external agency to work with the young person this was deemed to be a positive experience. The professional could see an end point to dealing with the young person. If the young person had failed to meet the required threshold to access the service, or the professional had not secured what they 
perceived to be the desired outcome for the family this was seen to be a negative experience.

"That particular one was good. I got everything that I wanted." (Housing Tenancy Officer, Stage one)

If the outcome was seen to be inadequate, all of the respondents, in stage one regardless of their professional background, were disappointed with the process. Additionally they were dissatisfied if, as a result of the panel, they either had additional tasks to complete in order for the family to access support or they felt the advice from the panel was ill informed or inadequate.

"They [the multi-agency panel] suggested that I find a parenting course so they were not very forthcoming with the information." (Qualified Teacher, Stage one)

This professional view of a positive or negative outcome of the referral process often encompassed the original purpose and result of the referral. A positive professional experience was directly related to the outcome for the family.

\section{Discussion}

The CAF was introduced by the New Labour government as a means to support families at the earliest opportunity, as well as enhance multi-agency working and professional communication (CWDC, 2009; DfES, 2006). In the absence of any new policy initiatives the CAF or a shorter variation of this is still be utilised within current practice. However, Brandon et al., (2006) commented that established use of the CAF demonstrated minimal commonality, due to the diversity of local authority use and implementation. Use of the CAF within the study reported here did reveal commonality with regard to the use of the CAF. Within the local authorities in which the research focused, there was a requirement of the CAF form to be used as a referral mechanism to access support services. Further to this professionals tended to utilise the form for similar reported issues as well as to access particular services.

A number of implications for practice emanated from this local authority requirement. Firstly, professionals obliged to engage in this process and complete assessments originate 
from a diverse range of professional backgrounds. For example within this study, Education Welfare Officers, Family Workers, Tenancy Enforcement Officers, and Community Safety Officers, as well as professionals working within education and social care completed CAF forms to enable the families they were working with to access support services. Secondly, due to the diversity of the professionals, particular professional groups experienced difficulty in the completion of the form and their role within the process. Brandon et al., (2006), Gilligan and Manby (2008), and White et al., (2009) all found the CAF was being utilised with a dual purpose: an assessment tool and a referral tool. However, in the study reported here this dual purpose resulted in the CAF form being perceived as a referral tool or as the professionals referred to it 'a means to an end' rather than the holistic assessment form it was envisaged to be (DfES, 2006).

Similar to the study reported here White et al., (2009) also found a number of professionals struggled with the frame and structure of the form itself, claiming that it did not allow for the full narrative of families' stories to be told. Professionals either chose to omit answers from the form altogether, or gave scant information that was thought to be inadequate by other professionals who came into contact with the family. A number of the professionals had adapted ways to provide the information they felt necessary to tell the families' stories, often adding to the margins of the form; or placing the information into existing boxes where it had little or no relevance. In addition to this, professionals were also found to be reluctant to offer information that they felt was not relevant to their own remit or expertise. In contrast to White et al., (2009) these practices were only evident as being utilised by particular professional groups. Issues with the completion of the form and comprehension of the information required for the form was experienced, specifically, by the professionals working within enforcement roles such as community safety, housing tenancy and education welfare. This was especially noticeable during stage one of the data collection period.

More recently, Holmes and McDermid (2016) have reported professional concerns with the perceived level of responsibility required in completing the CAF form. This is in addition to a lack of training provided for professionals required to complete a CAF form. Collins and McCray (2012) concluded there was a difference, in the use of the CAF form; dependent on whether the professional was vocationally or professionally qualified. In the study reported 
here, whilst there were clear differences in the completion of the CAF there was uniform agreement in the use of the CAF form. Indeed, both vocationally and professionally qualified professionals were seen to refer to the CAF as a 'means to an end': the CAF form had to be completed in order to access the required service. However, professionals who were working within enforcement agencies experienced particular difficulties with their role within the process. These professionals' expressed the view that having to complete the form was beyond the remit of their professional role. Additionally, the assessment aspect of the process was contradictory, ambiguous and confusing for both the professional and the family involved. In one sense the professional had an enforcement remit with the power of enforcing serious consequences for the family. Having to complete a CAF form to access support services, added a supportive dimension to their relationship with the family, which did not fit with their role or the family's perception of or frame of reference of the professional.

\section{Conclusion}

This study used a relatively small sample. Consequently the results and conclusions drawn cannot be generalised. However, it did include the views of professionals working across four local authorities. The study was conducted within the same geographical area of England and the local authorities adopted similar administrative systems. The respondents within the four local authorities reported similar experiences, frustrations, difficulties, and barriers. This would suggest, although tentatively, the findings may be replicable across other local authorities, as well as other countries who utilise a similar holistic approach to their social care practices and services. However, a much broader study and further exploration of this within other local authorities in different areas of England would be needed to be confident in drawing less tentative conclusions.

Currently, in England, the ideal is to provide early intervention services. This policy is thought to have a number of benefits, such as financial savings and cost efficiency, preventing the deterioration of negative behaviours and to enhancing the protection of children and young people (NEF 2009, 2012, Allen \& Duncan Smith 2008, Allen, 2011; Children's Commissioner 2019; Early Intervention Fund 2018). However, a direct result of utilising the form as a referral tool is the particular difficulties experienced by certain 
professional groups in completing assessment tasks. As has been demonstrated, in this paper, the use of the CAF as a referral tool resulted in a variety of professionals completing the form. This resulted in a number of consequences for the professional and, on occasion, for the family and young person. Recommendations for practice include the suggestion that Local Authorities should reconsider their use of the CAF as a referral tool, for access to statutory agencies and commissioned support services. The result of this practice prevents the CAF form being utilised as the intended holistic assessment. With the current political climate and ongoing implications of cost cutting, further research should explore the use of early intervention services, as well as the consequences of referral mechanisms utilised in order to access these services. 


\section{References}

Adamson, S., \& Deverell, C. (2009). CAF in the country: implementing the Common Assessment Framework in a rural area. Child \& Family Social Work, 14(4), 400-409.

Allen, G. (2011) 'Early Intervention: The next steps an independent report to her majesty's government'. Available at: http://www.dwp.gov.uk/docs/early-intervention-next-steps.pdf (Accessed 25/01/11)

Allen, G. \& Duncan Smith, I. (2008) Early Intervention: Good Parents, Great Kids, Better Citizens. London UK: Centre for Social Justice and the Smith Institute.

Brandon, M., Howe, A., Dagley, V., Salter, C. \& Warren, C. (2006) 'What appears to be helping or hindering practitioners in implementing the common assessment framework and lead professional working?', Child Abuse Review, 15(6), pp.396-413.

Braun, V. \& Clarke, V. (2006) 'Using thematic analysis in psychology', Qualitative Research in Psychology, 3 pp.77-101.

Children Act (2004) Children Act. London: Her Majesty's Stationery Office.

Children Act (1989) Children Act. London: Her Majesty's Stationery Office.

Children's Commissioner (2019) Estimating Children's Services spending o vulnerable children. Vulnerability technical spend report London: Children's Commissioner for England Children's Workforce Development Council (2009) Early Identification, assessment of needs and intervention. The Common Assessment Framework for children and young people. A Guide for Practitioners. London: The Stationery Office.

Collins, F. \& McCray, J. (2012) 'Partnership working in services for children: Use of the common assessment framework', Journal of Interprofessional Care, 26 (2), pp.134-140.

Corby, B. (2006) 'The role of child care social work in supporting families with children in need and providing protective services-past, present and future', Child Abuse Review, 15 (3), pp.159-177. 
Department for Children Schools and Families (2009a) 14-19 Briefing Making Change Happen. UK: Crown Copyright.

Department for Education (2012) Early Intervention grant FAQs. London: Department for Education.

Department for Education and Skills (2006) Common Assessment Framework for children and young people: practitioners' guide. Integrated working for to improve outcomes for children and young people. Leeds: Children's Workforce Development Council.

Department for Education and Skills (2004) Every Child Matters: Change for Children. London: Crown Copyright.

Early Intervention Fund (2018) Realising the Potential of Early Intervention. London: Early Intervention Fund

Economic and Social Research Council (2010) Framework for Research Ethics (FRE). UK: Economic and Social Research Council. Retrieved 03/11/2012

Family Rights Group (2018) Care Crisis Review options for change. London: Family Rights Group

France, A. \& Utting, D. (2005) 'The paradigm of 'risk and protection-focused prevention' and its impact on services for children and families', Children \& Society, 19 (2), pp.77-90.

Featherstone, B., Morris, K., \& White, S. (2013). A Marriage Made in Hell: Early Intervention Meets Child Protection. British Journal of Social Work.

Gergen, K.J. (1999) An invitation to social constructionism. London: Sage.

Gilligan, P. \& Manby, M. (2008) 'The Common Assessment Framework: Does the reality match the rhetoric?' Child \& Family Social Work, 13 (2), pp.177-187.

Glass, N. (1999) 'Sure start: The development of an early intervention programme for young children in the United Kingdom', Children \& Society, 13 (4), pp.257-364. 
Hardiker, P. (ed.) (1999) Children still in need, indeed: Prevention across five decades. London UK: Blackwell Science.

Holmes, L. and McDermid, S (2016) The Common Assessment Framework: the impact of the lead professional on families and professionals as part of a continuum of care in England. Child and Family Social Work, 21 pp. 530-538

Houston, S. (2001) 'Beyond social constructionism: Critical realism and social work', British Journal of Social Work, 31 (6), pp.845.

Lindsay, G., Cullen, S., Band, S., Cullen, M. \& Strand, S. (2009) Evaluation of the Parenting Early Intervention Programme. Warwick: University of Warwick.

Lucas, S. (2017). A children's space? Participation in multi-agency early intervention. Child and Family Social Work, 22 pp. 1383-1390

New Economics Foundation (2012) The Wisdom of Prevention Long-term planning, upstream investment and early action to prevent harm. London: New Economics Foundation.

New Economics Foundation (2009) Backing the Future: Why investing in children is good for us all. London: New Economics Foundation.

Parton, N. (2003) 'Rethinking professional practice: The contributions of social constructionism and the feminist 'ethics of care.' British Journal of Social Work, 33 (1), pp.116.

Payne, M. (1997) Modern social work theory. London: Macmillan.

Pithouse, A., Hall, C., Peckover, S. \& White, S. (2009) 'A tale of two CAFs: The impact of the electronic common assessment framework', British Journal of Social Work, 39 (4), pp.599612.

Puffett, N. (2013) 'Early intervention under threat as biggest cuts strike deprived areas', Children \& Young People Now, pp.8-9. 
Puffett, N. (2012) 'Early intervention grant raises questions over fairness and bias', Children \& Young People Now, pp.8-9.

Sahin, F. (2006) 'Implications of social constructionism for social work', Asia Pacific Journal of Social Work \& Development (Department of Social Work, National University of Singapore), 16 (1), pp.57-65.

Schon, D. (1987) Educating the reflective practitioner. San Francisco CA: Jossey-Bass.

Schon, D. (1983) The reflective pracitioner: How professionals think in action. New York: Basic Books.

Schultheiss, D. \& Wallace, E. (2012) 'An introduction to social constructionism in vocational psychology and career development', in Mcllveen, P. and Schultheiss, D. (eds.) Social constructionism in vocational psychology and career development. The Netherlands: Sense Publishers.

Schwandt, T. (2003) 'Three epistemological stances for qualittaive inquiry: Interpretivism, hermeneutics and social constructionism.', in Denzin, N. and Lincoln, Y. (eds.) The landscape of qualitative research: Theories and issues. Thousand Oaks, California: Sage.

Sheppard, M. (2009) 'Social support use as a parental coping strategy: Its impact on outcome of child and parenting problems-A six month follow up', British Journal of Social Work, 39 pp.1427-1446.

Social Exclusion Task Force (2007) Reaching Out: Think Family. London: Social Exclusion Task Force.

Sodha, S. (2009) 'Kidulthood: Life as a pre-teen in the UK today'. Available at: http://www.actionforchildren.org.uk/uploads/media/36/8702.pdf. (Accessed 03/11/10)

Tunstill, J. (ed.) (1997) Implementing the family support clauses of the 1989 Children Act. legislative, professional and organisational obstacles. London: Routledge. 
Weinberg, D. (2012) 'The social construction of self-knowledge: A commentary on the legacy of Melvin Pollner', American Sociologist, 43 (1), pp.76-84.

White, S., Hall, C. \& Peckover, S. (2009) 'The descriptive tyranny of the common assessment framework: Technologies of categorization and professional practice in child welfare', British Journal of Social Work, 39 (7), pp.1197-1217 